\title{
Subsequent Cholecystectomy Is The Most Important Factor for Recurrent Biliary Event-Free Survival in High-Risk Acute Cholecystitis Patients after Gallbladder Drainage
}

\section{Chi-Chih Wang}

Chung Shan Medical University Hospital

Ming-Chang Tsai

Chung Shan Medical University Hospital

Yen-Pin Huang

Changhua Christian Hospital

Wen-Hsin Huang

China Medical University Hospital

Tsung-Yu Tsai

China Medical University Hospital

Wen-Wei Sung

Chung Shan Medical University Hospital

Tzu-Wei Yang

Chung Shan Medical University Hospital

Jaw- Town Lin

China Medical University Hospital

Chun-Che Lin

China Medical University Hospital

Hsu-Heng Yen ( $\sim$ blaneyen@gmail.com )

Changhua Christian Hospital

\section{Research Article}

Keywords: cholecystectomy, percutaneous transhepatic gallbladder drainage, subsequent cholecystectomy, recurrent biliary event, recurrent biliary event-free survival, clinical management

Posted Date: December 10th, 2020

DOI: https://doi.org/10.21203/rs.3.rs-118655/v1 
License: (c) (i) This work is licensed under a Creative Commons Attribution 4.0 International License. Read Full License 


\section{Abstract}

Background and Aims: Cholelithiasis is a disease with increasing prevalence over the decades. Gallbladder drainage is an alternative choice in critically ill patients who cannot tolerate early surgery for acute cholecystitis. In previous data, early or delayed cholecystectomy leads to less recurrent biliary events comparing to using a wait-and-see strategy. We wondered if the subsequent cholecystectomy strategy is the most important factor to improve recurrent biliary event-free survival after gallbladder drainage. The present study aimed to explore the most important factor to improve the clinical outcome after percutaneous transhepatic gallbladder drainage.

Methods: We studied 211 adult acute cholecystitis patients who received percutaneous transhepatic gallbladder drainage during index admission between July 2017 and December 2018 in Chung Shan Medical University Hospital and Changhua Christian Hospital. Patients who died during the index admission or lost follow-up within 30 days were excluded. We further divided these patients into those who received subsequent cholecystectomy within 2 months and those who received no cholecystectomy within 2 months. Recurrent biliary events, mortality and biliary event-related mortality were compared. Multivariate analysis was applied to find the most important factors of recurrent biliary event-free survival.

Results: There were 8 cases (13.6\%) in the subsequent cholecystectomy group that experienced recurrent biliary events, while 39 cases (32.2\%) experienced recurrent biliary events in the no cholecystectomy within 2 months group. The proportion and average recurrent biliary events per person were all significantly lower in the subsequent cholecystectomy group. The recurrent biliary event-related mortality difference is insignificant. The most decisive factor to determine recurrent biliary event-free survival is whether a subsequent cholecystectomy performed or not (HR:0.485, 95\% Cl: 0.250-0.941, p=0.032).

Conclusion: Subsequent cholecystectomy can decrease further recurrent biliary events and improve recurrent biliary event-free survival in high risk patients with acute cholecystitis that accepted percutaneous transhepatic gallbladder drainage initially.

\section{Introduction}

Cholelithiasis is a disease with increasing prevalence in both developed[1, 2], and less developed areas nowadays[3]. Cholecystitis is an inflammatory process located in the gallbladder[4] that occurs in patients with a history of symptomatic gallstones[5,6]. Acalculous cholecystitis occurs sometimes[7, 8]. Clinical management of acute cholecystitis, such as early cholecystectomy (CCY), percutaneous transhepatic gallbladder drainage (PT-GBD), and endoscopic ultrasonography guide gallbladder drainage (EUS-GBD), are based on disease severity [9]. PT-GBD and EUS-GBD were selected especially in critically ill patients who cannot tolerate surgery initially[10, 11].

According to the timing of $\mathrm{CCY}$, it can be further classified as early CCY, which is performed initially after cholecystitis diagnosis, or delayed CCY. As previous literature showed[12-14], compared to delayed CCY, 
early CCY for cases within 72 hours of symptom onset was associated with lower mortality rates and complication rates in the majority of cases. Meanwhile, early CCY is a better choice than delayed CCY regarding hospital stay and medical expenses for treatment in some studies[14]. Still some references show that delayed CCY has a higher proportion of laparoscopy intervention[15] and a lower complication rate[16]. Although CCY is the only definitive therapy for acute cholecystitis[4, 9, 17], there are patients with high short-term comorbidity risk for surgery. The patients who need surgery intervention are suggested to be evaluated using the Charlson Comorbidity Index (CCI)[18-20] or the American Society of Anesthesiologists physical status classification (ASA-PS)[21, 22]; PT-GBD is useful for managing high surgical risk patients compared with conservative treatment $[9,23,24]$. CCY can decrease further recurrent biliary events (RBEs) [25, 26], while the surgery timing after patients with acute cholecystitis have undergone PT-GBD is still in debate[27-32]. Currently, there is no strong evidence to suggest who has survival benefits from subsequent CCY after initial PT-GBD, but a similar concept in choledocholithiasis demonstrated that a prophylactic $\mathrm{CCY}$ in acute cholangitis patients who underwent sphincterotomy showed survival benefit compared to the wait-and-see approach[33].

In general, most subsequent CCY was expected to be beneficial and performed within 2 months after initial PT-GBD, so we conduct a retrospective hospital base cohort study to evaluate the most valuable factors to RBE-free survival after initial PT-GBD for complicated acute cholecystitis.

\section{Methods}

This is a retrospective cohort study collecting cases of accepted PT-GBD during index admission from July 2017 to December 2018 in Chung Shan Medical University Hospital (CSMUH) and Changhua Christian Hospital (CCH). This study was performed in accordance with the Declaration of Helsinki and was approved by the Institutional Review Board (IRB) of CSMUH and CCH (No. 200402); documentation of informed consent was waived because the study was conducted retrospectively.

\section{Study design}

We collected 211 adult patients with accepted PT-GBD during index admission from July 2017 to December 2018 in CSMUH and CCH. Patients who underwent PT-GBD for cancer obstruction were excluded. The diagnosis of acute cholecystitis was based on Tokyo Guideline 2018. Some patients suffered from both acute cholangitis and acute cholecystitis were managed by PT-GBD and endoscopic retrograde cholangiopancreatography in our study population. Because the purpose of this study was to evaluate the most important factors that affect RBE free survival after initial PT-GBD insertion, patients who died during index admission were excluded. Patients who are alive and lost follow-up within 30 days were excluded from further analysis. We further divided these patients into those with CCY within 2 months before PT-GBD removal (subsequent CCY) and those with no CCY within 2 months after the index admission. All the patients were followed up to their expired date if happened, up to their last hospital visit record or December 31, 2019. 
We compared the demographic data, like age, gender, follow-up time, the decisive diagnosis image methods, disease severity at index admission, laboratory (lab) data, baseline CCl score, underlying diseases, and the proportion of laparoscopic/open CCY procedures between the subsequent CCY group and no CCY within 2 months group. The definition of RBE included ER visits and admissions due to biliary events, such as cholangitis, acute biliary pancreatitis and cholecystitis. We evaluate the outcomes of these patients using average RBEs, RBE case numbers, overall mortality, and RBE-related mortality. RBE-related mortality was defined as mortality events due to RBEs during hospitalization or mortality events after critical discharge. We evaluate the decisive factors using multi-variate analysis for clinical conditions, laboratory data, interventions and comorbidity after acute cholelithiasis underwent PT-GBD by RBE-free survival to build the adequate clinical practice and possible outcomes.

\section{Data processing and statistical analysis}

The raw data were collected using Microsoft Excel Office Open XML. Kaplan-Meier survival analyses were conducted using SPSS version 19. The important clinical parameters and parameters that achieve statistically significant differences in univariate analysis of RBE-free survival in table 3 are evaluated using multivariate analysis with cox regression model.

The data obtained from the study were processed using chi-square $(\chi 2)$ tests or Fisher's exact test for categorical variables, one-way analyses of variance (ANOVA) for continuous variables, and Kaplan-Meier survival for disease-free survival curves. A two-tailed P-value of 0.05 was considered statistically significant

\section{Results}

A total 211 of adult patients who underwent PT-GBD were selected from the hospital database from July 2017 to December 2018 in CSMUH and CCH. After exclusion of 10 patients who expired during index admission and 8 patients who accepted PT-GBD as a rescue treatment for bile duct cancer obstruction, we included 193 adult patients who underwent PT-GBD at index admission for acute cholecystitis. We further excluded 13 cases, who were alive because of lost follow up within 30 days after discharge. Among 180 patients selected for analysis, 59 patients underwent subsequent CCY and the other 121 patients didn't accept CCY within 2 months before PT-GBD removal as a definite treatment. Eventually, there were 11 patients who underwent $\mathrm{CCY}$ because of RBEs or frequent biliary colic in the no CCY within 2 months group. The flow chart of this study is shown in Figure 1.

\section{Subsequent CCY group vs. No CCY within 2 months group}

The average age in the subsequent CCY group was $71.1 \pm 14.6$, which is significantly younger than those in the no CCY within 2 months group ( $p=0.022)$, with an average age of $76.4 \pm 14.1 \mathrm{in}$. We could find that the proportion of sepsis, the proportion of underlying dementia, and CCl score $(4.2 \pm 2.2$ vs. $5.4 \pm 2.3, p<$ 0.001 ) were significantly higher in the no CCY within 2 months group. Other underlying diseases of the parameters of the $\mathrm{CCl}$ score were similar between the two groups. Regarding the status of $\mathrm{CCY}$, only 11 
patients $(9.1 \%)$ underwent CCY in the no subsequent CCY within 2 months group, while $94.9 \%$ patients underwent laparoscopic CCY under a subsequent CCY strategy in CCY within 2 months group. Only $81.8 \%$ of patients underwent laparoscopic $\mathrm{CCY}$ if $\mathrm{CCY}$ was chose as a rescue management in the no CCY within 2 months group when RBEs occurred. But the proportion of laparoscopic CCY did not meet statistical significance between these 2 groups. The detailed demographic data are shown in table 1.

There were 8 cases, which represent $13.6 \%$ of patients, that experienced RBEs once in the subsequent CCY group, while 39 cases (32.2\%) experienced RBEs in the no CCY within 2 months group (1 RBE: 27 patients, 2 RBEs: 10 patients, 3 RBEs: 1 patient, 4 RBEs: 1 patients). The average number of RBE is higher in the no CCY within 2 months group comparing CCY within 2 months group ( 0.446 vs. 0.136$)$. The overall mortality rate is $16.5 \%$ in the no CCY within 2 months group, and it is significantly higher than the overall mortality rate $(5.1 \%)$ in the subsequent CCY group. But RBE-related mortality didn't reach statistical significance between these two groups. The outcome comparisons are listed in table 2.

\section{Decisive factors of RBE-free survival}

We evaluate the true value of treatment for cholelithiasis using RBE-free survival, which demonstrated a survival curve free from RBEs and overall mortality. In univariate analysis, those age $\geq 79$ had 1.682 times the risk for RBEs or mortality (95\% Cl: 1.014-2.790, $\mathrm{p}=0.044)$, while gallbladder (GB) rupture in index admission had 2.665 times the risk ( $95 \% \mathrm{Cl}$ : $1.069-6.644, \mathrm{p}=0.036$ ) comparing to no GB rupture. The group with no CCY within 2 months had increased risk (HR:2.383, 95\% Cl: 1.244-4.564, p=0.009) in RBEfree survival compared to the subsequent $\mathrm{CCY}$ group. The detailed information about univariate analysis of disease severity, demographic data, $\mathrm{CCl}$ score, underlying disease condition, and CCY status is listed in table 3. After placing age ( $<79$ vs. $\geq 79$ ), GB rupture and subsequent CCY attempt and $\mathrm{CCl}$ score ( $\leq 8$ vs $>8$ ) into multivariate analysis, only subsequent CCY maintained a significantly decreased risk of RBE-free survival, with 2.061 times the risk $(\mathrm{Cl}: 1.063-3.998, \mathrm{p}=0.032)$ if subsequent $\mathrm{CCY}$ is not performed. Age (HR:1.477, 95\% Cl: 0.885-2.467, p=0.136), GB rupture (HR: 2.191, 95\% Cl: 0.873-5.501, $p=0.095$ ), and CCl score $>8$ (HR: 1.616, 95\% Cl: 0.763-3.425, $p=0.210)$ had slightly increased risk in RBEs or mortality without statistical significance. Detailed multivariate analysis of RBE-free survival according to the clinical parameters is demonstrated in table 4 .

\section{RBE-free survival}

RBE-free survival of patients who underwent PT-GBD due to acute cholecystitis was significantly better $(p=0.007)$ if subsequent CCY was performed, with RBE-free survival being $81.9 \%$ in the next year and $75.0 \%$ at the end of the follow-up period, compared to $56.6 \%$ in the first year and $48.2 \%$ at the end of the follow-up period if subsequent CCY is not performed. The results are shown in Figure 2.

\section{Discussion}

We found only 59 among 180 patients, which represent $32.78 \%$ of total patients, who accepted subsequent CCY after PT-GBD for acute cholecystitis in our data from two medical centers. At the same 
time, the subsequent CCY strategy can have a higher laparoscopic CCY proportion (94.9\%) than the waitand-see policy (81.8\%). When comparing the benefits of laparoscopic CCY versus open CCY in previous literature, laparoscopic CCY results in a shorter hospital stay[34-36], less post-operative complications[36], being safer in the early trimester of pregnancy[37], and having a lower mean use of analgesia[35]. Although some studies expose laparoscopic CCY as not being a cost-effective investment under economic analysis[38], laparoscopic CCY provides more benefits than open CCY. A subsequent CCY policy is better than the wait-and-see policy theoretically. In our study, subsequent CCY can significantly decrease the RBE cases without affecting the RBE mortality compared to the no CCY within 2 months policy. In a previous systemic review or randomized control trial, comparisons between CCY and no further surgical treatment are relatively rare. But one randomized control trial showed nonsignificant differences in the laparoscopic CCY group and no further intervention group regarding RBEs [39] and overall mortality[40], which means non-operative management may be an option in specific patients. Our results indicate that having no CCY within 2 months after acute cholecystitis after PT-GBD increases further RBEs, but such a decision does not significantly affect the survival rate directly. There are similar results comparing the outcomes of laparoscopic CCY and PT-GBD in high-risk cholecystitis patients without significant differences in mortality rate[41].

GB rupture, $\mathrm{CCl}>8$, age older than 79 years-old, and subsequent $\mathrm{CCY}$ play important roles in RBE-free survival, but multivariate analysis showed that only subsequent CCY significantly influenced the RBE-free survival after those with acute cholecystitis underwent PT-GBD. Acute cholecystitis patients usually accepted risk evaluation by ASA-PS or $\mathrm{CCl}$ score after initial diagnosis, and the patients that underwent PT-GBD initially represent either those in older age or those with some severe underlying disease. Although the severity of underlying diseases is important to future outcomes, our result showed the most important factor of RBE-free survival was whether subsequent CCY was performed or not. Subsequent CCY should be planned after the clinical condition of patient improves if laparoscopic CCY was not performed right after acute cholecystitis was diagnosed. The method of CCY, either laparoscopic or open, had little protective effect if not performed as a subsequent CCY strategy.

There are limitations and some questions in our study. Although surgery is the standard of treatment for patients with gallbladder drainage, lots of patients in Taiwan refused further CCY because of old age and influence of traditional culture. That's why many cases in our study do not accept subsequent CCY even after PT-GBD treatment. Because this is a retrospective cohort study, the decision of surgical intervention, even subsequent $\mathrm{CCY}$, is highly associated with current patient condition and experience of physicians. We noticed that patients were older, had higher $\mathrm{CCl}$ scores, and there was a higher proportion of dementia in the no CCY within 2 months group; this is an important selection bias. We believed this is the reason for significantly higher overall mortality in the no CCY within 2 months group rather than the influences of the differences of further RBEs. Meanwhile, RBE-free survival was chosen as an evaluation method that can balance RBE effect and mortality events due to invasive intervention. But the overall mortality rate is low in our analysis, and the RBE-free survival mainly reflects the reality of RBEs. 
In conclusion, we found that subsequent $\mathrm{CCY}$ can decrease further RBEs and improve RBE-free survival in patients of acute cholecystitis who accepted PT-GBD initially.

\section{Declarations}

Competing interests statement:

All authors declare no potential financial and non-financial conflicts of interest.

Funding:

The authors received funding from Changhua Christian Hospital (http://www2.cch.org.tw/cch_english/) for this work: numbers 109-CCHIRP-008 and 108-CCHIRP-018 for Dr. Hsu-Heng Yen

\section{Author contributions statement:}

Conceptualization, Chi-Chih Wang and Ming-Chang Tsai; Data curation, Yen-Pin Huang; Formal analysis, Tsung-Yu Tsai, Wen-Wei Sung and Tzu-Wei Yang; Funding acquisition, Hsu-Heng Yen; Investigation, TzuWei Yang; Methodology, Chi-Chih Wang and Chun-Che Lin; Supervision, Chun-Che Lin and Hsu-Heng Yen; Validation, Ming-Chang Tsai, Tsung-Yu Tsai, Wen-Wei Sung and Jaw- Town Lin; Writing - original draft, Chi-Chih Wang; Writing - review \& editing, Yen-Pin Huang and Wen-Hsin Huang.

\section{References}

1. Shaffer EA. Epidemiology and risk factors for gallstone disease: has the paradigm changed in the 21st century? Curr Gastroenterol Rep. 2005;7(2):132-40. Epub 2005/04/02. doi: 10.1007/s11894005-0051-8. PubMed PMID: 15802102.

2. Shaheen NJ, Hansen RA, Morgan DR, Gangarosa LM, Ringel Y, Thiny MT, et al. The burden of gastrointestinal and liver diseases, 2006. Am J Gastroenterol. 2006;101(9):2128-38. Epub 2006/07/20. doi: 10.1111/j.1572-0241.2006.00723.x. PubMed PMID: 16848807.

3. Rahman GA. Cholelithiasis and cholecystitis: changing prevalence in an African community. J Natl Med Assoc. 2005;97(11):1534-8. Epub 2005/12/13. PubMed PMID: 16334500; PubMed Central PMCID: PMCPMC2594906.

4. Bagla P, Sarria JC, Riall TS. Management of acute cholecystitis. Curr Opin Infect Dis. 2016;29(5):50813. Epub 2016/07/19. doi: 10.1097/QC0.0000000000000297. PubMed PMID: 27429137.

5. Shabanzadeh DM. Incidence of gallstone disease and complications. Curr Opin Gastroenterol. 2018;34(2):81-9. Epub 2017/12/20. doi: 10.1097/MOG.0000000000000418. PubMed PMID: 29256915.

6. Friedman GD. Natural history of asymptomatic and symptomatic gallstones. Am J Surg. 1993;165(4):399-404. Epub 1993/04/01. doi: 10.1016/s0002-9610(05)80930-4. PubMed PMID: 
8480871.

7. Shapiro MJ, Luchtefeld WB, Kurzweil S, Kaminski DL, Durham RM, Mazuski JE. Acute acalculous cholecystitis in the critically ill. Am Surg. 1994;60(5):335-9. Epub 1994/05/01. PubMed PMID: 8161083.

8. Huffman JL, Schenker S. Acute acalculous cholecystitis: a review. Clin Gastroenterol Hepatol. 2010;8(1):15-22. Epub 2009/09/15. doi: 10.1016/j.cgh.2009.08.034. PubMed PMID: 19747982.

9. Yokoe M, Hata J, Takada T, Strasberg SM, Asbun HJ, Wakabayashi G, et al. Tokyo Guidelines 2018: diagnostic criteria and severity grading of acute cholecystitis (with videos). J Hepatobiliary Pancreat Sci. 2018;25(1):41-54. Epub 2017/10/17. doi: 10.1002/jhbp.515. PubMed PMID: 29032636.

10. Ito K, Fujita N, Noda Y, Kobayashi G, Kimura K, Sugawara T, et al. Percutaneous cholecystostomy versus gallbladder aspiration for acute cholecystitis: a prospective randomized controlled trial. AJR Am J Roentgenol. 2004;183(1):193-6. Epub 2004/06/23. doi: 10.2214/ajr.183.1.1830193. PubMed PMID: 15208137.

11. Gomi H, Solomkin JS, Schlossberg D, Okamoto K, Takada T, Strasberg SM, et al. Tokyo Guidelines 2018: antimicrobial therapy for acute cholangitis and cholecystitis. J Hepatobiliary Pancreat Sci. 2018;25(1):3-16. Epub 2017/11/02. doi: 10.1002/jhbp.518. PubMed PMID: 29090866.

12. Chandler CF, Lane JS, Ferguson P, Thompson JE, Ashley SW. Prospective evaluation of early versus delayed laparoscopic cholecystectomy for treatment of acute cholecystitis. Am Surg. 2000;66(9):896-900. Epub 2000/09/19. PubMed PMID: 10993625.

13. Gutt CN, Encke J, Koninger J, Harnoss JC, Weigand K, Kipfmuller K, et al. Acute cholecystitis: early versus delayed cholecystectomy, a multicenter randomized trial (ACDC study, NCT00447304). Ann Surg. 2013;258(3):385-93. Epub 2013/09/12. doi: 10.1097/SLA.0b013e3182a1599b. PubMed PMID: 24022431.

14. Okamoto K, Suzuki K, Takada T, Strasberg SM, Asbun HJ, Endo I, et al. Tokyo Guidelines 2018 : flowchart for the management of acute cholecystitis. J Hepatobiliary Pancreat Sci. 2018;25(1):55-72. Epub 2017/10/19. doi: 10.1002/jhbp.516. PubMed PMID: 29045062.

15. Wang CC, Tsai MC, Wang YT, Yang TW, Chen HY, Sung WW, et al. Role of Cholecystectomy in Choledocholithiasis Patients Underwent Endoscopic Retrograde Cholangiopancreatography. Sci Rep. 2019;9(1):2168. Epub 2019/02/20. doi: 10.1038/s41598-018-38428-z. PubMed PMID: 30778100; PubMed Central PMCID: PMCPMC6379409.

16. Ozkardes AB, Tokac M, Dumlu EG, Bozkurt B, Ciftci AB, Yetisir F, et al. Early versus delayed laparoscopic cholecystectomy for acute cholecystitis: a prospective, randomized study. Int Surg. 2014;99(1):56-61. Epub 2014/01/22. doi: 10.9738/INTSURG-D-13-00068.1. PubMed PMID: 24444271 ; PubMed Central PMCID: PMCPMC3897343.

17. Ansaloni L, Pisano M, Coccolini F, Peitzmann AB, Fingerhut A, Catena F, et al. 2016 WSES guidelines on acute calculous cholecystitis. World J Emerg Surg. 2016;11:25. Epub 2016/06/17. doi: 10.1186/s13017-016-0082-5. PubMed PMID: 27307785; PubMed Central PMCID: PMCPMC4908702. 
18. Charlson ME, Pompei P, Ales KL, MacKenzie CR. A new method of classifying prognostic comorbidity in longitudinal studies: development and validation. J Chronic Dis. 1987;40(5):373-83. Epub 1987/01/01. doi: 10.1016/0021-9681(87)90171-8. PubMed PMID: 3558716.

19. Quan H, Sundararajan V, Halfon P, Fong A, Burnand B, Luthi JC, et al. Coding algorithms for defining comorbidities in ICD-9-CM and ICD-10 administrative data. Med Care. 2005;43(11):1130-9. Epub 2005/10/15. doi: 10.1097/01.mlr.0000182534.19832.83. PubMed PMID: 16224307.

20. Charlson M, Szatrowski TP, Peterson J, Gold J. Validation of a combined comorbidity index. J Clin Epidemiol. 1994;47(11):1245-51. Epub 1994/11/01. doi: 10.1016/0895-4356(94)90129-5. PubMed PMID: 7722560.

21. Keats AS. The ASA classification of physical status-a recapitulation. Anesthesiology. 1978;49(4):233-6. Epub 1978/10/01. doi: 10.1097/00000542-197810000-00001. PubMed PMID: 697075.

22. Eakin JL, Bader AM. ASA physical status classification system: Is it consistent amongst providers and useful in determining need for pre-operative evaluation resources? J Clin Anesth. 2017;39:73-4. Epub 2017/05/13. doi: 10.1016/j.jclinane.2017.03.028. PubMed PMID: 28494912.

23. Viste A, Jensen D, Angelsen JH, Hoem D. Percutaneous cholecystostomy in acute cholecystitis; a retrospective analysis of a large series of 104 patients. BMC Surg. 2015;15:17. Epub 2015/04/16. doi: 10.1186/s12893-015-0002-8. PubMed PMID: 25872885; PubMed Central PMCID: PMCPMC4357156.

24. Kortram K, de Vries Reilingh TS, Wiezer MJ, van Ramshorst B, Boerma D. Percutaneous drainage for acute calculous cholecystitis. Surg Endosc. 2011;25(11):3642-6. Epub 2011/06/04. doi: 10.1007/s00464-011-1771-5. PubMed PMID: 21638173.

25. Gurusamy KS, Davidson C, Gluud C, Davidson BR. Early versus delayed laparoscopic cholecystectomy for people with acute cholecystitis. Cochrane Database Syst Rev. 2013; (6):CD005440. Epub 2013/07/03. doi: 10.1002/14651858.CD005440.pub3. PubMed PMID: 23813477.

26. Alvino DML, Fong ZV, McCarthy CJ, Velmahos G, Lillemoe KD, Mueller PR, et al. Long-Term Outcomes Following Percutaneous Cholecystostomy Tube Placement for Treatment of Acute Calculous Cholecystitis. J Gastrointest Surg. 2017;21(5):761-9. Epub 2017/02/23. doi: 10.1007/s11605-0173375-4. PubMed PMID: 28224465.

27. Han IW, Jang JY, Kang MJ, Lee KB, Lee SE, Kim SW. Early versus delayed laparoscopic cholecystectomy after percutaneous transhepatic gallbladder drainage. J Hepatobiliary Pancreat Sci. 2012;19(2):187-93. Epub 2011/09/23. doi: 10.1007/s00534-011-0458-6. PubMed PMID: 21938408.

28. Choi JW, Park SH, Choi SY, Kim HS, Kim TH. Comparison of clinical result between early laparoscopic cholecystectomy and delayed laparoscopic cholecystectomy after percutaneous transhepatic gallbladder drainage for patients with complicated acute cholecystitis. Korean J Hepatobiliary Pancreat Surg. 2012;16(4):147-53. Epub 2012/11/01. doi: 10.14701/kjhbps.2012.16.4.147. PubMed PMID: 26388926; PubMed Central PMCID: PMCPMC4575000. 
29. Jung WH, Park DE. Timing of Cholecystectomy after Percutaneous Cholecystostomy for Acute Cholecystitis. Korean J Gastroenterol. 2015;66(4):209-14. Epub 2015/10/24. doi:

10.4166/kjg.2015.66.4.209. PubMed PMID: 26493506.

30. Sakamoto T, Fujiogi M, Matsui H, Fushimi K, Yasunaga H. Timing of cholecystectomy after percutaneous transhepatic gallbladder drainage for acute cholecystitis: a nationwide inpatient database study. HPB (Oxford). 2019. Epub 2019/11/17. doi: 10.1016/j.hpb.2019.10.2438. PubMed PMID: 31732466.

31. Yamada K, Yamashita Y, Yamada T, Takeno S, Noritomi T. Optimal timing for performing percutaneous transhepatic gallbladder drainage and subsequent cholecystectomy for better management of acute cholecystitis. J Hepatobiliary Pancreat Sci. 2015;22(12):855-61. Epub 2015/10/20. doi: 10.1002/jhbp.294. PubMed PMID: 26479740.

32. Inoue K, Ueno T, Nishina O, Douchi D, Shima K, Goto S, et al. Optimal timing of cholecystectomy after percutaneous gallbladder drainage for severe cholecystitis. BMC Gastroenterol. 2017;17(1):71. Epub 2017/06/02. doi: 10.1186/s12876-017-0631-8. PubMed PMID: 28569137; PubMed Central PMCID: PMCPMC5452332.

33. McAlister VC, Davenport E, Renouf E. Cholecystectomy deferral in patients with endoscopic sphincterotomy. Cochrane Database Syst Rev. 2007;(4):CD006233. Epub 2007/10/19. doi: 10.1002/14651858.CD006233.pub2. PubMed PMID: 17943900.

34. Johansson M, Thune A, Nelvin L, Stiernstam M, Westman B, Lundell L. Randomized clinical trial of open versus laparoscopic cholecystectomy in the treatment of acute cholecystitis. Br J Surg. 2005;92(1):44-9. Epub 2004/12/08. doi: 10.1002/bjs.4836. PubMed PMID: 15584058.

35. Eldar S, Sabo E, Nash E, Abrahamson J, Matter I. Laparoscopic versus open cholecystectomy in acute cholecystitis. Surg Laparosc Endosc. 1997;7(5):407-14. Epub 1998/02/12. PubMed PMID: 9348622.

36. Kiviluoto T, Siren J, Luukkonen P, Kivilaakso E. Randomised trial of laparoscopic versus open cholecystectomy for acute and gangrenous cholecystitis. Lancet. 1998;351(9099):321-5. Epub 1998/07/04. doi: 10.1016/S0140-6736(97)08447-X. PubMed PMID: 9652612.

37. Sedaghat N, Cao AM, Eslick GD, Cox MR. Laparoscopic versus open cholecystectomy in pregnancy: a systematic review and meta-analysis. Surg Endosc. 2017;31(2):673-9. Epub 2016/06/22. doi: 10.1007/s00464-016-5019-2. PubMed PMID: 27324332.

38. Silverstein A, Costas-Chavarri A, Gakwaya MR, Lule J, Mukhopadhyay S, Meara JG, et al. Laparoscopic Versus Open Cholecystectomy: A Cost-Effectiveness Analysis at Rwanda Military Hospital. World J Surg. 2017;41(5):1225-33. Epub 2016/12/03. doi: 10.1007/s00268-016-3851-0. PubMed PMID: 27905020.

39. Vetrhus M, Soreide O, Nesvik I, Sondenaa K. Acute cholecystitis: delayed surgery or observation. A randomized clinical trial. Scand J Gastroenterol. 2003;38(9):985-90. Epub 2003/10/09. doi: 10.1080/00365520310004056. PubMed PMID: 14531537. 
40. Schmidt M, Sondenaa K, Vetrhus M, Berhane T, Eide GE. Long-term follow-up of a randomized controlled trial of observation versus surgery for acute cholecystitis: non-operative management is an option in some patients. Scand J Gastroenterol. 2011;46(10):1257-62. Epub 2011/07/09. doi: 10.3109/00365521.2011.598548. PubMed PMID: 21736531.

41. Loozen CS, van Santvoort HC, van Duijvendijk P, Besselink MG, Gouma DJ, Nieuwenhuijzen GA, et al. Laparoscopic cholecystectomy versus percutaneous catheter drainage for acute cholecystitis in high risk patients (CHOCOLATE): multicentre randomised clinical trial. BMJ. 2018;363:k3965. Epub 2018/10/10. doi: 10.1136/bmj.k3965. PubMed PMID: 30297544; PubMed Central PMCID:

PMCPMC6174331 at www.icmje.org/coi_disclosure.pdf declare no support from any organisation for the submitted work, no financial relationships with any organizations that might have an interest in the submitted work, and no other relationships or activities that could appear to have influenced the submitted work.

\section{Tables}

Table 1 Demographic data of patients underwent percutaneous transhepatic gallbladder drainage 


\begin{tabular}{|c|c|c|c|c|c|}
\hline \multirow[t]{2}{*}{ Study group } & \multicolumn{2}{|c|}{$\begin{array}{l}\text { Subsequent CCY within } \\
2 \text { months } \\
\mathrm{N}=59\end{array}$} & \multicolumn{2}{|c|}{$\begin{array}{l}\text { No CCY within } 2 \\
\text { months, } N=121\end{array}$} & \multirow[t]{2}{*}{$P$ value } \\
\hline & $\mathrm{N}$ & $\mathrm{SD} ; \%$ & $\mathrm{~N}$ & SD; \% & \\
\hline Age (SD) & 71.1 & 14.6 & 76.4 & 14.1 & 0.022 \\
\hline \multicolumn{6}{|l|}{ Gender } \\
\hline Male & 36 & $61.0 \%$ & 75 & $62.0 \%$ & 0.900 \\
\hline Female & 23 & $39.0 \%$ & 46 & $38.0 \%$ & \\
\hline Follow up time (days) & 354 & 234 & 370 & 215 & 0.645 \\
\hline Diagnosis tool & & & & & NA \\
\hline CT & 52 & $88.1 \%$ & 96 & $79.3 \%$ & \\
\hline MRI & 1 & $1.7 \%$ & 4 & $3.3 \%$ & \\
\hline Sonography & 6 & $10.2 \%$ & 21 & $17.4 \%$ & \\
\hline \multicolumn{6}{|l|}{ Disease severity } \\
\hline Sepsis & 12 & $20.3 \%$ & 42 & $34.7 \%$ & 0.048 \\
\hline \multicolumn{6}{|l|}{ Combined cholangitis } \\
\hline & 21 & $35.6 \%$ & 35 & $28.9 \%$ & 0.364 \\
\hline GB rupture & 1 & $1.7 \%$ & 6 & $5.0 \%$ & 0.288 \\
\hline \multicolumn{6}{|l|}{ Lab data } \\
\hline WBC & 13462 & 6291 & 13608 & 5981 & 0.880 \\
\hline T/B (gm/dl) & 2.4 & 2.2 & 2.6 & 2.6 & 0.736 \\
\hline $\mathrm{Cr}$ & 1.4 & 1.6 & 1.5 & 1.6 & 0.743 \\
\hline CRP & 15.0 & 10.1 & 11.9 & 9.8 & 0.151 \\
\hline \multicolumn{6}{|l|}{ Comorbidity } \\
\hline CCI score & 4.2 & 2.2 & 5.4 & 2.3 & $<0.001$ \\
\hline MI & 4 & $6.8 \%$ & 11 & $9.1 \%$ & 0.598 \\
\hline CHF & 9 & $15.3 \%$ & 28 & $23.1 \%$ & 0.219 \\
\hline PVD & 1 & $1.7 \%$ & 3 & $2.5 \%$ & 0.738 \\
\hline CVA & 12 & $20.3 \%$ & 23 & $19.0 \%$ & 0.832 \\
\hline Dementia & 1 & $1.7 \%$ & 20 & $16.5 \%$ & 0.004 \\
\hline
\end{tabular}




\begin{tabular}{|llllll|}
\hline Chronic pulmonary disease & 1 & $1.7 \%$ & 11 & $9.1 \%$ & 0.062 \\
\hline Rheumatologic disease & 0 & $0.0 \%$ & 0 & $0.0 \%$ & N/A \\
\hline Peptic ulcer disease & 14 & $23.7 \%$ & 27 & $22.3 \%$ & 0.832 \\
\hline Mild liver disease & 3 & $5.1 \%$ & 6 & $5.0 \%$ & 0.971 \\
\hline Diabetes & 23 & $33.8 \%$ & 45 & $37.2 \%$ & 0.816 \\
\hline $\begin{array}{l}\text { Diabetes with chronic } \\
\text { complication }\end{array}$ & 0 & $0.0 \%$ & 3 & $2.5 \%$ & 0.301 \\
\hline Hemiplegia or paraplegia & 5 & $8.5 \%$ & 4 & $44.4 \%$ & 0.135 \\
\hline Renal disease & 1 & $1.7 \%$ & 9 & $7.4 \%$ & 0.119 \\
\hline $\begin{array}{l}\text { Malignancy ; including leukemia } \\
\text { and lymphoma }\end{array}$ & 0 & $0.0 \%$ & 1 & $0.8 \%$ & 0.672 \\
\hline Moderate or severe liver disease & 3 & $17.6 \%$ & 14 & $11.6 \%$ & 0.163 \\
\hline Metastatic solid tumor & 0 & $0.0 \%$ & 5 & $4.1 \%$ & 0.134 \\
\hline AlDS & 0 & $0.0 \%$ & 1 & $0.8 \%$ & 0.672 \\
\hline Total CCY & 59 & $100 \%$ & 11 & $9.1 \%$ & $<0.0001$ \\
\hline Laparoscopic CCY proportion & 56 & $94.9 \%$ & 9 & $81.8 \%$ & 0.122 \\
\hline Open CCY proportion & 3 & $5.1 \%$ & 2 & $18.2 \%$ & \\
\hline
\end{tabular}

$\mathrm{SD}=$ standard deviation, $\mathrm{GB}=$ gallbladder, $\mathrm{CT}=$ Computed Tomography, $\mathrm{MRI}=$ Magnetic resonance imaging, $\mathrm{WBC}=$ white blood cell, $\mathrm{T} / \mathrm{B}=$ total bilirubin, $\mathrm{Cr}=$ creatinine, $\mathrm{CRP}=\mathrm{C}$ reactive protein, $\mathrm{CCl}$ score= Charlson Comorbidity Index score, $\mathrm{Ml}=$ Myocardial infarction, $\mathrm{PVD}=$ Peripheral vascular disease, $\mathrm{CVA}=$ cerebrovascular disease, AIDS= acquired immune deficiency syndrome, NA= Not Applicable

Table 2 Outcomes of patients underwent percutaneous transhepatic gallbladder drainage

\begin{tabular}{|c|c|c|c|c|c|}
\hline \multirow[t]{2}{*}{ Study group } & \multicolumn{2}{|c|}{$\begin{array}{l}\text { Subsequent CCY within } 2 \text { months, } \\
\mathrm{N}=59\end{array}$} & \multicolumn{2}{|c|}{$\begin{array}{l}\text { No CCY within } 2 \text { months, } \\
\mathrm{N}=121\end{array}$} & \multirow[t]{2}{*}{$\begin{array}{l}P \\
\text { value }\end{array}$} \\
\hline & $\mathrm{N}$ & Rang; \% & $\mathrm{N}$ & Rang; \% & \\
\hline RBEs* & 0 & $0-1$ & 0 & $0-4$ & 0.003 \\
\hline RBE case number & 8 & $13.6 \%$ & 39 & $32.2 \%$ & 0.007 \\
\hline Overall mortality & 3 & $5.1 \%$ & 20 & $16.5 \%$ & 0.031 \\
\hline $\begin{array}{l}\text { RBE related } \\
\text { mortality }\end{array}$ & 1 & $1.7 \%$ & 5 & $4.1 \%$ & 0.392 \\
\hline
\end{tabular}

$\mathrm{CCY}=$ cholecystectomy, $\mathrm{SD}=$ standard deviation, $\mathrm{RBE}=$ recurrent biliary event 
*Median and range due to non-normal distribution

Table. 3 Univariate analysis of RBE-free survival according to the clinical parameters. 


\begin{tabular}{|c|c|c|c|c|}
\hline & $\mathrm{N}$ & HR & $95 \% \mathrm{Cl}$ & $\mathrm{p}$ \\
\hline Age (<79 vs $\geq 79)$ & $89 / 91$ & 1.682 & $1.014-2.790$ & 0.044 \\
\hline Gender ( $F$ vs $M)$ & $69 / 111$ & 1.421 & $0.868-2.325$ & 0.162 \\
\hline Sepsis & $126 / 54$ & 1.085 & $0.640-1.842$ & 0.762 \\
\hline Combined cholangitis & $124 / 56$ & 0.784 & $0.450-1.366$ & 0.391 \\
\hline GB rupture & $173 / 7$ & 2.665 & $1.069-6.644$ & 0.036 \\
\hline $\mathrm{CCl}$ score $(\leq 5$ vs $>5)$ & $112 / 68$ & 1.238 & $0.755-2.031$ & 0.397 \\
\hline $\mathrm{CCl}$ score $(\leq 6$ vs $>6)$ & $137 / 43$ & 1.215 & $0.710-2.080$ & 0.477 \\
\hline $\mathrm{CCl}$ score ( $\leq 7$ vs $>7$ ) & $154 / 26$ & 1.723 & $0.952-3.117$ & 0.072 \\
\hline $\mathrm{CCl}$ score $(\leq 8$ vs $>8)$ & $167 / 13$ & 2.026 & $0.965-4.253$ & 0.062 \\
\hline Any comorbidity ${ }^{1}$ & $91 / 89$ & 1.008 & $0.617-1.646$ & 0.975 \\
\hline Comorbidity $^{2}(\leq 3$ vs $>3$ ) & $164 / 16$ & 1.232 & $0.562-2.703$ & 0.603 \\
\hline Comorbidity ( $\leq 2$ vs $>2$ ) & $143 / 37$ & 1.101 & $0.617-1.965$ & 0.746 \\
\hline Comorbidity ( $\leq 1$ vs $>1$ ) & $97 / 83$ & 1.233 & $0.755-2.015$ & 0.403 \\
\hline $\mathrm{Ml}$ & $165 / 15$ & 0.847 & $0.340-2.111$ & 0.721 \\
\hline $\mathrm{CHF}$ & $143 / 37$ & 0.932 & $0.497-1.747$ & 0.826 \\
\hline PVD & $176 / 4$ & 1.329 & $0.325-5.444$ & 0.692 \\
\hline CVA & $154 / 35$ & 0.986 & $0.535-1.814$ & 0.963 \\
\hline Dementia & $159 / 21$ & 1.653 & $0.863-3.166$ & 0.130 \\
\hline Chronic pulmonary disease & $168 / 12$ & 0.794 & $0.288-2.188$ & 0.656 \\
\hline Rheumatologic disease & $180 / 0$ & NA & NA & NA \\
\hline Peptic ulcer disease & $139 / 41$ & 0.988 & $0.554-1.764$ & 0.968 \\
\hline Mild to severe liver disease & $154 / 26$ & 1.509 & $0.820-2.775$ & 0.186 \\
\hline Moderate or severe liver disease & $163 / 17$ & 1.316 & $0.627-2.763$ & 0.468 \\
\hline Diabetes & $112 / 68$ & 1.209 & $0.736-1.987$ & 0.453 \\
\hline Hemiplegia or paraplegia & $171 / 9$ & 0.045 & $0.001-4.611$ & 0.189 \\
\hline Renal disease & $170 / 10$ & 1.331 & $0.534-3.318$ & 0.539 \\
\hline Malignancy; including leukemia and lymphoma & $179 / 1$ & 4.344 & $0.595-31.717$ & NA \\
\hline Metastatic solid tumor & $168 / 12$ & 0.925 & $0.336-2.547$ & 0.881 \\
\hline
\end{tabular}




\begin{tabular}{|lllll|} 
AIDS & $179 / 1$ & 88.999 & $8.070-981.503$ & NA \\
\hline Any CCY status & $110 / 70$ & 0.583 & $0.335-1.017$ & 0.057 \\
\hline Subsequent CCY vs others & $\mathbf{5 9 / 1 2 1}$ & $\mathbf{2 . 3 8 3}$ & $\mathbf{1 . 2 4 4 - 4 . 5 6 4}$ & $\mathbf{0 . 0 0 9}$ \\
\hline CCY (No vs Laparoscopic) & $110 / 65$ & 0.588 & $0.333-1.038$ & 0.067 \\
\hline CCY (No vs Laparotomy) & $110 / 5$ & 0.509 & $0.070-3.699$ & 0.505 \\
\hline
\end{tabular}

$\mathrm{RBE}=$ recurrent biliary event, $\mathrm{GB}=$ gallbladder, $\mathrm{WBC}=$ white blood cell, $\mathrm{T} / \mathrm{B}=$ total bilirubin, $\mathrm{Cr}=$ creatinine, $\mathrm{CRP}=\mathrm{C}$ reactive protein, $\mathrm{CCl}$ score $=$ Charlson Comorbidity Index score, $\mathrm{Ml}=$ Myocardial infarction, $\mathrm{PVD}=$ Peripheral vascular disease, $C V A=$ Cerebrovascular disease, AIDS= acquired immune deficiency syndrome, NA= Not Applicable

${ }^{1}$ Include any $\mathrm{MI}, \mathrm{CVA}, \mathrm{COPD}, \mathrm{CHF}$, liver disease (moderate to severe)

${ }^{2}$ Numbers of comorbidity within $\mathrm{CCl}$ score system

Table. 4 Multivariate analysis of RBE free survival according to the clinical parameters. $(\mathrm{N}=178)$

\begin{tabular}{|lllll|}
\hline & $\mathrm{N}$ & $\mathrm{HR}$ & $95 \% \mathrm{Cl}$ & $\mathrm{p}$ \\
\hline Age $(<79$ vs $\geq 79)$ & $89 / 91$ & 1.477 & $0.885-2.467$ & 0.136 \\
\hline GB rupture & $173 / 7$ & 2.191 & $0.873-5.501$ & 0.095 \\
\hline CCl score $(\leq 8$ vs $>8)$ & $167 / 13$ & 1.616 & $0.763-3.425$ & 0.210 \\
\hline No CCY within 2 months vs subsequent CCY & $\mathbf{1 2 1 / 5 9}$ & $\mathbf{0 . 4 8 5}$ & $\mathbf{0 . 2 5 0 - 0 . 9 4 1}$ & $\mathbf{0 . 0 3 2}$ \\
\hline
\end{tabular}

$\mathrm{RBE}=$ recurrent biliary event, $\mathrm{GB}=$ gallbladder, $\mathrm{CCl}$ score= Charlson Comorbidity Index score, $\mathrm{CCY}=$ cholecystectomy

\section{Figures}




\section{Figure 1}

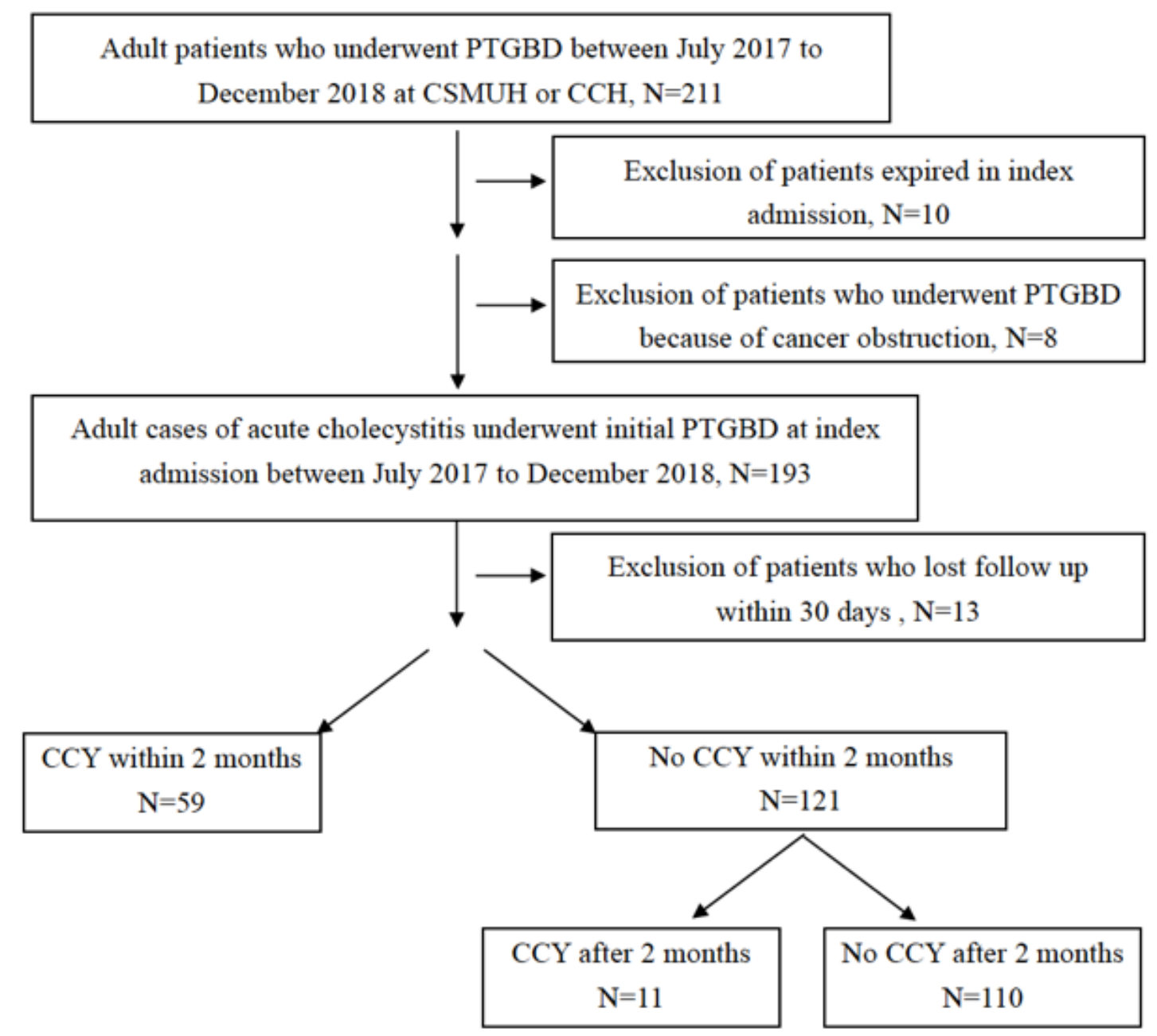

$\mathrm{CSMUH}=$ Chung Shan Medical University Hospital (75), $\mathrm{CCH}=$ Changhua Christian Hospital (136)

\section{Figure 1}

Flow chart for case selection and study design $\mathrm{CSMUH}=$ Chung Shan Medical University Hospital, $\mathrm{CCH}=$ Changhua Christian Hospital, PTGBD= percutaneous transhepatic gallbladder drainage, $\mathrm{CCY}=$ cholecystectomy 
Figure 2

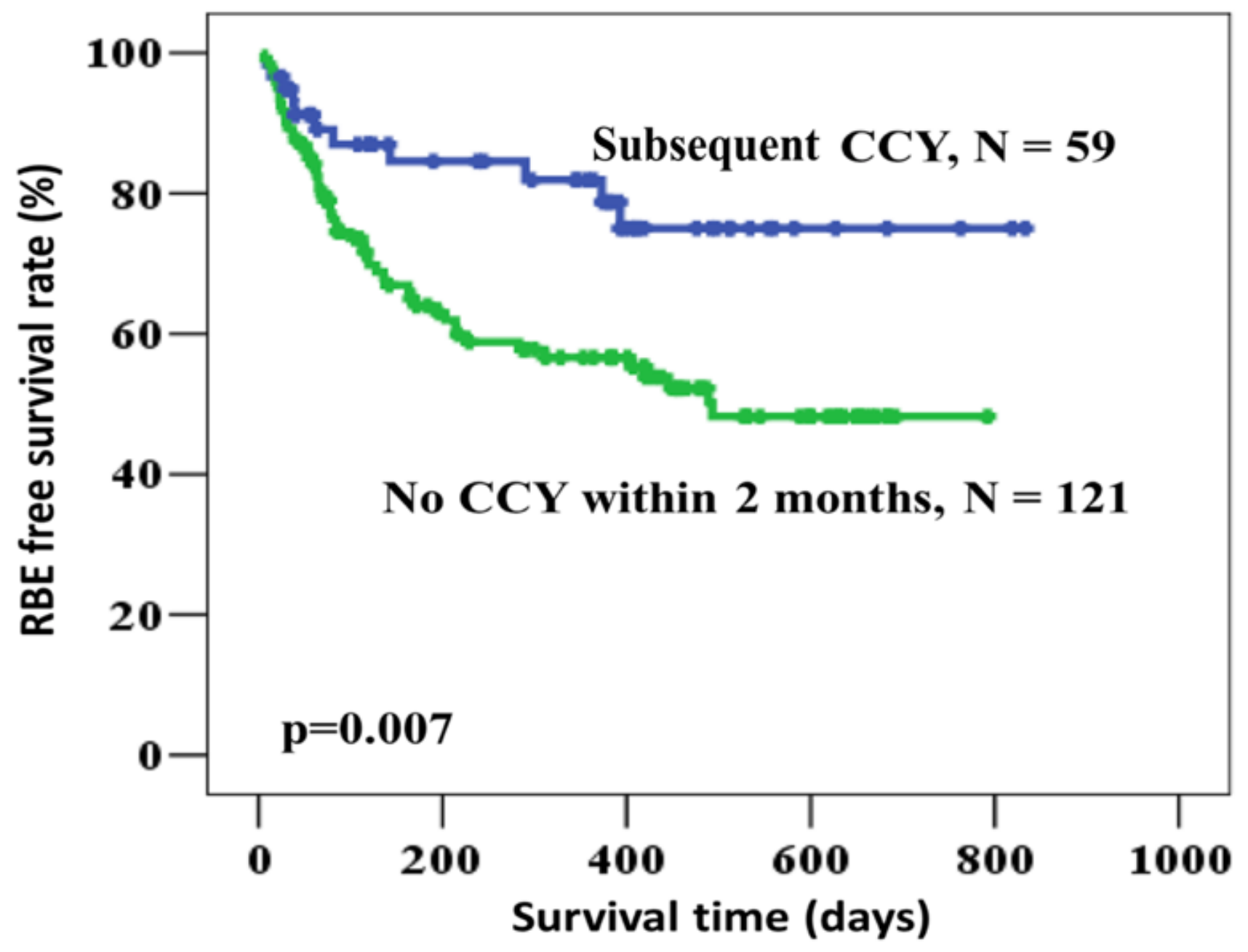

Figure 2

Recurrent biliary event-free survival comparison between subsequent CCY group and no CCY within 2 months group $\mathrm{RBE}=$ recurrent biliary event, $\mathrm{CCY}=$ cholecystectomy 